\title{
Informed choice about breast cancer prevention: randomized controlled trial of an online decision aid intervention
}

Ida J Korfage ${ }^{1,2}$, Andrea Fuhrel-Forbis ${ }^{2,3,4}$, Peter A Ubel ${ }^{5,6}$, Brian J Zikmund-Fisher ${ }^{2,3,7,8}$, Sarah M Greene ${ }^{9}$, Jennifer B McClure ${ }^{9}$, Dylan M Smith ${ }^{10}$, Sharon Hensley Alford ${ }^{11}$ and Angela Fagerlin ${ }^{2,3,12,13^{*}}$

See related Editorial by Juraskova and Bonner, http://breast-cancer-research.com/content/15/5/106

\begin{abstract}
Introduction: Tamoxifen and raloxifene are chemopreventive drugs that can reduce women's relative risk of primary breast cancer by 50\%; however, most women eligible for these drugs have chosen not to take them. The reasons for low uptake may be related to women's knowledge or attitudes towards the drugs. We aimed to examine the impact of an online breast cancer chemoprevention decision aid (DA) on informed intentions and decisions of women at high risk of breast cancer.

Methods: We conducted a randomized clinical trial, assessing the effect of a DA about breast cancer chemoprevention on informed choices about chemoprevention. Women $(n=585)$, 46- to 74-years old old, completed online baseline, post-test, and three-month follow-up questionnaires. Participants were randomly assigned to either an intervention group, a standard control group that answered questions about chemoprevention at baseline, or a three-month control group that did not answer questions about chemoprevention at baseline. The main outcome measures were whether women's intentions and decisions regarding chemoprevention drugs were informed, and whether women who viewed the DA were more likely to make informed decisions than women who did not view the DA, using a dichotomous composite variable 'informed choice' (yes/no) to classify informed decisions as those reflecting sufficient knowledge and concordance between a woman's decision and relevant attitudes.
\end{abstract}

Results: Analyses showed that more intervention than standard control participants (52.7\% versus 5.9\%) made informed decisions at post-test, $P<0.001$. At the three-month follow-up, differences in rates of informed choice between intervention (16.9\%) and both control groups (11.8\% and 8.0\%) were statistically non-significant, $P=0.067$.

Conclusions: The DA increased informed decision making about breast cancer chemoprevention, although the impact on knowledge diminished over time. This study was not designed to determine how much knowledge decision makers must retain over time. Examining informed decisions increases understanding of the impact of DAs. A standard for defining and measuring sufficient knowledge for informed decisions is needed.

Trial registration: ClinicalTrials.gov: NCT00967824

\footnotetext{
* Correspondence: fagerlin@med.umich.edu

${ }^{2}$ Center for Bioethics and Social Sciences in Medicine, University of Michigan,

300 North Ingalls, Ann Arbor, MI 48106-1248, USA

Full list of author information is available at the end of the article
} 


\section{Introduction}

Tamoxifen and raloxifene are chemopreventive drugs that can reduce women's relative risk of primary breast cancer by $50 \%[1,2]$. Tamoxifen has been available for chemoprevention for more than 10 years, and raloxifene was approved in 2006 for post-menopausal women. When the efficacy of these drugs for breast cancer prevention was established, it was initially believed they would provide a desirable option for reducing the risk of breast cancer and that these drugs might bring about a 'new era of preventive therapeutics that could revolutionize women's health'[3]. However, most women eligible for these drugs have chosen not to take them [4-8].

A number of factors relating to women's knowledge and attitudes towards these drugs appear to contribute to the low uptake. First, women are not necessarily aware of their availability - previous research found women's awareness of tamoxifen varied widely between ethnic groups, with white women most frequently reporting awareness of the drugs [9]. Second, women may not believe the drugs can truly reduce their risk of breast cancer [8,10-12]. Third, while raloxifene was originally designed to treat osteoporosis, tamoxifen was designed to prevent recurrence of breast cancer and, therefore, may have negative connotations [13]. Fourth, fear of potential side effects may inhibit positive attitudes toward taking chemoprevention drugs [5], including a perception that the potential risks (that is, increased risks of endometrial cancer, pulmonary embolism, stroke, deep vein thrombosis, cataracts, hormonal symptoms and sexual problems) outweigh the potential benefits of the drugs (that is, reduced risks of breast cancer and osteoporosis) $[4,5,7,10,12,14]$. Finally, many people, particularly when healthy, are opposed to taking preventive drugs on a regular basis $[5,12]$.

Deciding whether to start chemoprevention is a preference sensitive decision, meaning there is not one superior choice [15]. To make the best decision for themselves, individuals need unbiased information [16] to consider the risks and benefits of each choice as well as their values and goals.

At present, there is no standard measure of informed choice for cancer prevention or detection behaviors. In this manuscript we adapt the concept of the Multidimensional Measure of Informed Choice (MMIC) as developed by Marteau and colleagues, which relates to the dimensions of knowledge, people's attitudes regarding the choice options and the extent to which choice reflects attitudes $[17,18]$. This concept was, in turn, adapted from O'Connor and O'Brien-Pallas' [19] definition of an effective decision: 'one that is based on relevant knowledge, consistent with the decision-maker's values and behaviorally implemented.' Marteau's definition states that an informed choice to engage in chemoprevention behavior occurs when a woman: 1) has sufficient relevant knowledge about chemoprevention behavior; 2) has positive attitudes toward engaging in chemoprevention; and 3) engages in chemopreventive behavior. It also occurs when a woman: 1) has sufficient relevant knowledge about chemoprevention behavior; 2) negative attitudes toward engaging in chemoprevention; and 3) does not engage in chemopreventive behavior [17]. Although decisions resulting from other combinations of these factors are traditionally considered uninformed, either because of insufficient decision-relevant knowledge or because of incongruence between attitudes and behavior, we define a third type of informed decision; specifically, women with: 1) sufficient relevant knowledge; 2) ambivalent attitudes toward chemoprevention; and 3) who are undecided or uncertain about whether to engage in chemoprevention. Chemoprevention decisions are not time-sensitive in the same way that treatment decisions are and waiting to make a choice as a result of ambivalence is quite rational, given there is little cost to delay. We characterize the choice to delay decision-making about chemoprevention due to ambivalent or neutral attitudes as informed since women may still be in the process of making a decision; their lack of a decision accurately reflects their ambivalent attitudes.

To date, we are unaware of other studies that have assessed the impact of a decision aid (DA) on women's informed decisions about breast cancer chemoprevention. Aiming to address this gap, a randomized controlled trial was conducted in 2007/2008 to test a tailored, online breast cancer chemoprevention DA. The 'Guide to Decide' DA provided tailored information (see section 2.3 for details) to women at increased risk of breast cancer about the risks and benefits of tamoxifen and raloxifene [20]. Women's knowledge, attitudes and behavioral intentions to take chemoprevention drugs were assessed immediately after viewing the DA and their uptake behavior three months later. The primary outcomes were whether women's decisions regarding chemoprevention drugs were informed and whether women who viewed the DA were more likely to make informed decisions than women who did not view the DA.

\section{Methods}

\section{Participant recruitment}

After obtaining Institutional Review Board approval from the University of Michigan and two health care delivery systems (Henry Ford Health System in Detroit, MI and Group Health Cooperative in Seattle, WA) and registering the trial (http://ClinicalTrials.gov; number NCT00967824), electronic medical records were used to create a list of eligible women - specifically women at high risk of developing invasive breast cancer, defined by a five-year risk of $\geq 1.66 \%$ on the Breast Cancer Risk Assessment Tool (BCRAT, based on the Gail model) 
[19-21] and without contraindications to tamoxifen or raloxifene. We sent these women invitation letters with a description of the study, the study website, and a username and password. There was no racial bias in the selection of participants. Interested women logged in and were screened for final eligibility based on selfreport. Eligible women were between 40 and 74 years old, (as chemoprevention is only approved for those ages) and were post-menopausal (raloxifene is only approved for post-menopausal women [21]). Women were excluded if they reported a prior history of breast cancer or tamoxifen or raloxifene use, contraindications to tamoxifen or raloxifene, participation in the Study of Tamoxifen and Raloxifene (STAR) trial [21], terminal illness, or were currently pregnant or nursing.

\section{Randomization to intervention and control groups}

A total of 1,039 women gave their informed consent to participate in the study. Due to a computer error, only 1,012 of them were correctly randomized (see Figure 1, the flow diagram). This report is limited to the 585 of the $1,039(57.8 \%)$ women who completed the three-month follow-up survey.

After completing eligibility screening and the baseline questionnaire, participants were randomly assigned to one of three groups: intervention, standard control, or threemonth control as previously described by Fagerlin and colleagues [8] (Figure 1). Intervention group participants received the Guide to Decide DA (described below) immediately after randomization and then completed a post-test questionnaire. Standard control group participants did not receive the DA until they completed the three-month follow-up, but completed the same questionnaires as the

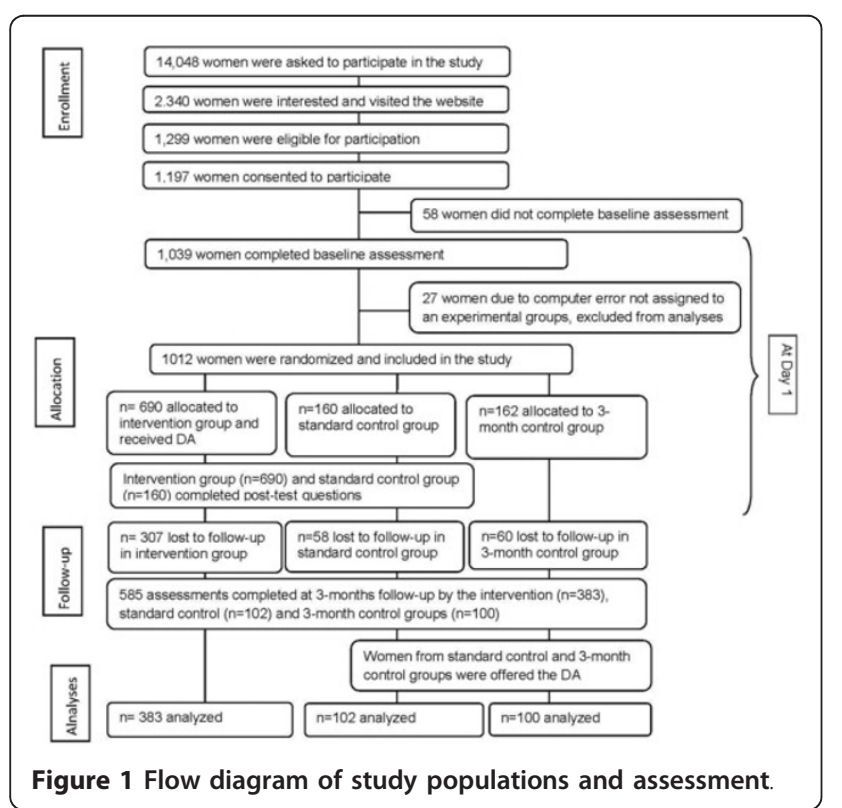

intervention group. Since participants in the standard control group might seek information (that is, "Google' tamoxifen and raloxifene) after having answered questions about chemoprevention without receiving any information, we included the three-month control group. Participants in this group answered chemoprevention questions at the three-month follow-up, but neither received the DA nor answered any questions about chemoprevention at the time of enrollment, which ensured the inclusion of a control group without previous exposure to chemoprevention information. Analyses examining the immediate effect of the DA compare participants from the intervention group to the standard control group, and analyses examining the longer-term effect of the DA compare participants from the intervention group to both control groups.

\section{The 'Guide to Decide' decision aid intervention}

The Guide to Decide DA provided general information about breast cancer, tamoxifen and raloxifene [1]. Women received tailored (personalized) information about their individual five-year risk of breast cancer according to their scores on the BCRAT [20]. Side effect rates were tailored to each woman's age and race. This information included estimates of the risks of endometrial cancer, blood clotting problems, cataracts, hormone symptoms, sexual problems, breast cancer and bone fractures. The DA was written at approximately an eighth grade reading level. Further details about the development and tailoring of the Guide to Decide DA intervention have been published previously [8].

\section{Measures}

\section{Knowledge of risks and benefits of chemoprevention}

Women's gist knowledge ('the ability to identify the essential point of the information presented') of the risks and benefits of each drug was measured through questions such as, 'Please tell us whether you think taking tamoxifen (or raloxifene) will make you less likely, more likely, or have no difference in the likelihood that you would experience each of the health conditions listed below.' Participants were then given a list of two risks (increased risk of hormonal symptoms and cataracts) and two benefits (decreased risk of broken bones and breast cancer) of tamoxifen (or raloxifene) and were asked to answer the likelihood question for each risk and benefit. Each question was asked for both tamoxifen and raloxifene. The intervention and standard control groups answered these knowledge questions at post-test and three-month followup, while the three-month control group only answered them at three-month follow-up.

Based on other researchers' work, we assessed distributions of accurate knowledge in the data and operationalized a 'sufficient level of decision-relevant knowledge' as answering at least $50 \%$ of the items ( 4 of 8 ) correctly 
and 'insufficient decision-relevant knowledge' as three or fewer correctly answered items [22].

\section{Attitudes toward chemopreventive drugs}

Women were asked, 'How good of a choice is taking tamoxifen (or raloxifene) as a way to reduce your chance of getting breast cancer?' ( 1 = 'For me it is not a good choice at all,' to $5=$ 'For me it is an extremely good choice'). Response options were worded to assess attitudes toward own behavior rather than attitudes toward tamoxifen in general (for example, a woman may feel chemoprevention is a good option for others but feel it is not a good choice for her personally). Responses 1 and 2 were classified as 'negative attitudes' and responses 4 and 5 as 'positive attitudes'. The midpoint response option 3 was classified as 'neutral attitudes' [22].

\section{Behavioral intentions}

Behavioral intentions to take chemoprevention drugs in the post-test survey were measured using 'Given what you know right now, how likely doyou think you are to take a breast cancer prevention drug in the next year?' ( 1 = 'not at all likely,' to 5 = 'extremely likely'). Responses 1 and 2 were classified as not likely to engage in chemoprevention behavior, response 3 was classified as neutral about engagement, and responses 4 and 5 were classified as likely to engage in chemoprevention behavior.

\section{Actual behavior}

Chemoprevention uptake behavior was measured in all three groups at follow-up by asking participants, 'Have you made a decision about whether or not to take a breast cancer prevention drug as a way to prevent breast cancer?' (1 = 'no decision yet'; 2 = 'decided to take Tamoxifen'; 3 = 'decided to take Raloxifene'; 4 = 'decided to take no drug').

\section{Informed or uninformed decision}

A dichotomous variable was created, 'informed decision,' (yes/no) representing participants with sufficient knowledge about chemoprevention behavior (assessed at posttest and follow-up), whose attitudes were concordant with their intentions (at post-test) or decisions (at follow-up) to engage in chemoprevention behavior.

According to Fuzzy Trace Theory [23], it is possible that participants made an initial decision at post-test based on their knowledge and attitudes at that time, and then forgot details by follow-up but remembered their general decision. These participants would, therefore, make a decision at follow-up based on their initial (post-test) knowledge and feelings. Three different 'informed decision' scores were calculated to account for the various ways participants may have arrived at an informed decision. Post-test knowledge, attitudes and intentions were used for the 'post-test informed decision' score. Follow-up knowledge, attitudes and behavior were used for the 'follow-up informed decision' score. Finally, post-test knowledge and follow-up attitudes and behavior were used for the 'latent knowledge informed decision' score.

\section{Covariates}

At baseline, age, race and ethnicity, and educational background were assessed. Educational background was condensed into three levels of education (high school or less, some college or trade school, and bachelor's degree or higher).

Participants completed standardized individual difference measures of subjective numeracy [24,25] and health, using the single item, 'How would you rate your health?' (1 = poor, 2 = fair, 3 = good, $4=$ very good and $5=$ excellent).

\section{Analyses}

We calculated means, standard deviations and frequencies to describe the participants and experimental groups. Inferential statistics include t-tests, analysis of variance, and Pearson chi-square analysis (2-tailed significance).

\section{Results}

\section{Participants}

A total of 585 women completed the study through the three-month follow-up (see Figure 1 for details on participant flow through the intervention). Table 1 describes participants' baseline characteristics. On average, participants were $61.6(\mathrm{SD}=5.2)$ years old, mostly white (98\%) and well educated $(71 \%$ had at least a bachelor's degree). BCRAT scores ranged from $1.7 \%$ to $19.1 \%(\mathrm{M}=2.67, \mathrm{SD}=1.37)$.

\section{Post-test knowledge, attitudes and behavioral intentions} More intervention participants (62\%) than standard control participants $(7 \%)$ met the criteria for 'sufficient knowledge,' $\mathrm{X}^{2}(1)=97.53, P<.001$ (answering at least 4 out of 8 questions correctly) (Table 2).

When asked 'How good of a choice is taking a breast cancer prevention drug as a way to reduce your chance of getting breast cancer?', 75\% of the intervention group and $62 \%$ of the standard control group indicated negative attitudes toward taking chemoprevention themselves. Intervention participants reported 19\% neutral attitudes and $6 \%$ positive attitudes, and standard control participants reported $35 \%$ neutral attitudes and $3 \%$ positive attitudes (Table 2). Distribution of attitudes varied significantly between the intervention and standard control groups, $\left(\mathrm{X}^{2}(2)=12.64, P=.002\right)$.

Intervention participants $(4 \%)$ were more likely to intend to start chemoprevention than standard control participants (3\%), $\mathrm{X}^{2}(2)=6.38, P=0.041$ (Table 2).

At post-test, participants in the intervention group were not more likely to demonstrate alignment of attitudes and intentions than those in the standard control group, $\mathrm{X}^{2}(1)$ $=0.077, P=0.78$ (data not shown). 
Table 1 Baseline variables for women who completed entire study

\begin{tabular}{lllll}
\hline & $\begin{array}{l}\text { Intervention } \\
(\boldsymbol{n}=\mathbf{3 8 3})\end{array}$ & $\begin{array}{l}\text { Standard control } \\
(\boldsymbol{n}=\mathbf{1 0 2})\end{array}$ & $\begin{array}{l}\text { Three-month control } \\
(\boldsymbol{n}=\mathbf{1 0 0})\end{array}$ & Between-groups differences \\
\hline Age, mean (SD) & $61.50(5.05)$ & $62.10(5.25)$ & $61.51(5.63)$ & $\mathrm{F}(2,582)=0.55, P=.58$ \\
Age, over 60 & $249(65.0 \%)$ & $67(65.7 \%)$ & $65(65.0 \%)$ & $X^{2}(2)=0.02, P=.99$ \\
$\begin{array}{l}\text { Education } \\
\quad \text { High school education or less }\end{array}$ & $19(5.0 \%)$ & $3(2.9 \%)$ & $7(7.0 \%)$ & $X^{2}(4)=3.69, P=.45$ \\
$\quad$ Some college or trade school & $84(22.2 \%)$ & $29(28.4 \%)$ & $26(26.0 \%)$ & \\
$\quad$ Four-year college degree or more & $276(72.8 \%)$ & $70(68.6 \%)$ & $67(67.0 \%)$ & \\
Race & & & $0(0 \%)$ & $X^{2}(2)=0.53, P=.77$ \\
$\quad$ Hispanic & $1(0.3 \%)$ & $0(0 \%)$ & $99(99.0 \%)$ & $X^{2}(2)=0.96, P=.62$ \\
$\quad$ White & $374(97.7 \%)$ & $99(97.1 \%)$ & $0(0 \%)$ & $X^{2}(2)=1.06, P=.59$ \\
$\quad$ Black & $2(0.5 \%)$ & $0(0 \%)$ & $2.82(2.16)$ & $F(2,582)=1.06, P=.35$ \\
BCRAT score (SD) & $2.67(1.19)$ & $2.55(0.92)$ & $4.29(0.99)$ & $F(2,582)=1.87, P=.16$ \\
Subjective Numeracy Scale & $4.48(0.94)$ & $4.53(0.95)$ & \\
\hline
\end{tabular}

\section{Post-test informed choice}

In the intervention group, $53 \%$ of the decisions about intentions to take chemoprevention were informed, in that participants had both sufficient knowledge and alignment of attitudes and intentions (Table 3 ). In the majority of cases (89\%), these were decisions of women who had sufficient knowledge, negative attitudes toward uptake and no intentions to take tamoxifen or raloxifene. Uninformed decisions were mainly due to low levels of decisionrelevant knowledge. Compared to intervention participants, fewer standard control participants (6\%) made an informed decision $\left(\mathrm{X}^{2}(1)=71.97, P<0.001\right.$, Table 3$)$. Most (93.1\%) standard control participants did not have sufficient knowledge to make an informed decision (Table 2).

Table 2 Effects of DA: post-test measures of knowledge, attitudes, and intentions

\begin{tabular}{|c|c|c|c|c|c|}
\hline & $\begin{array}{c}\text { Intervention } \\
(n=383)\end{array}$ & $\begin{array}{c}\text { Standard } \\
\text { control } \\
(n=102)\end{array}$ & $\begin{array}{c}\text { Three-month control }(n= \\
100)^{\mathrm{a}}\end{array}$ & $\begin{array}{l}\text { Between-groups } \\
\text { differences }\end{array}$ & \\
\hline \multicolumn{6}{|l|}{ Post-test } \\
\hline \multirow[t]{2}{*}{ Knowledge } & $\begin{array}{l}\text { Insufficient ( } \leq 50 \% \\
\text { correct) }\end{array}$ & $146(38.1 \%)$ & $95(93.1 \%)$ & & $X^{2}(197.53, P<.001$ \\
\hline & Sufficient & & $237(61.9 \%)$ & $7(6.9 \%)$ & \\
\hline \multirow[t]{3}{*}{ Attitudes } & Negative & $284(74.9 \%)$ & $61(61.6 \%)$ & & $\begin{array}{c}X^{2}(2)=12.64, P= \\
.002\end{array}$ \\
\hline & Neutral & & $72(19.0 \%)$ & $35(35.4 \%)$ & \\
\hline & Positive & & $23(6.1 \%)$ & $3(3.0 \%)$ & \\
\hline \multirow[t]{3}{*}{$\begin{array}{l}\text { Intention for } \\
\text { uptake }\end{array}$} & Not likely & $323(85.2 \%)$ & $78(77.2 \%)$ & & $\begin{array}{c}X^{2}(2)=6.38, P= \\
.041\end{array}$ \\
\hline & Neutral & & $40(10.6 \%)$ & $20(19.8 \%)$ & \\
\hline & Likely & & $16(4.2 \%)$ & $3(3.0 \%)$ & \\
\hline \multicolumn{6}{|c|}{ Three-month follow-up } \\
\hline \multirow[t]{2}{*}{ Knowledge } & $\begin{array}{l}\text { Insufficient }(\leq 50 \% \\
\text { correct) }\end{array}$ & $288(75.2 \%)$ & $87(85.3 \%)$ & $88(88.0 \%)$ & $\begin{array}{c}X^{2}(2)=10.71, P= \\
.005\end{array}$ \\
\hline & Sufficient & & $95(24.8 \%)$ & $15(14.7 \%)$ & $12(12.0 \%)$ \\
\hline \multirow[t]{3}{*}{ Attitudes } & Negative & $280(75.1 \%)$ & $68(69.4 \%)$ & $59(62.8 \%)$ & $\begin{array}{c}X^{2}(4)=7.84, P= \\
.098\end{array}$ \\
\hline & Neutral & & $83(22.3 \%)$ & $24(24.5 \%)$ & $30(31.9 \%)$ \\
\hline & Positive & & $10(2.7 \%)$ & $6(6.1 \%)$ & $5(5.3 \%)$ \\
\hline \multirow[t]{4}{*}{$\begin{array}{l}\text { Uptake at follow- } \\
\text { up }\end{array}$} & No decision & $171(44.8 \%)$ & $67(65.7 \%)$ & $70(70.0 \%)$ & $\begin{aligned} X^{2}(4) & =29.06, P \\
& <.001\end{aligned}$ \\
\hline & Take tamoxifen & & 0 & 0 & 0 \\
\hline & Take raloxifene $e^{\mathbf{a}}$ & & $2(0.5 \%)$ & 0 & 0 \\
\hline & Decided no drug & & 209 (54.7\%) & 35 (34.3\%) & $30(30.0 \%)$ \\
\hline
\end{tabular}

a Three-month control group did not complete measures at post-test. 
Table 3 Informed decisions: post-test, latent, and three-month follow-up, frequencies (\%)

\begin{tabular}{|c|c|c|c|c|}
\hline & $\begin{array}{l}\text { Intervention } \\
(n=383)\end{array}$ & $\begin{array}{l}\text { Standard control }(n= \\
102)\end{array}$ & $\begin{array}{l}\text { Three-month control }(n= \\
100)^{a}\end{array}$ & $\begin{array}{l}\text { Between-groups } \\
\text { differences }\end{array}$ \\
\hline \multicolumn{5}{|l|}{ Post-test informed decisions ${ }^{b}$} \\
\hline Negative attitudes, uptake unlikely & $180(47.0 \%)$ & $4(3.9 \%)$ & - & \\
\hline $\begin{array}{l}\text { Neutral attitudes, uptake neither likely nor } \\
\text { unlikely }\end{array}$ & $15(3.9 \%)$ & $2(2.0 \%)$ & - & \\
\hline Positive attitudes, uptake likely & $7(1.8 \%)$ & 0 & - & \\
\hline Total post-test informed decisions & $202(52.7 \%)$ & $6(5.9 \%)$ & & $X^{2}(1)=71.97, P<0.001$ \\
\hline \multicolumn{5}{|l|}{ Follow-up informed decisions ${ }^{b}$} \\
\hline Negative attitudes, decided against drug & $48(12.5 \%)$ & $6(5.9 \%)$ & $1(1.0 \%)$ & \\
\hline Neutral attitudes, no decision made & $17(4.4 \%)$ & $6(5.9 \%)$ & $7(7.0 \%)$ & \\
\hline Positive attitudes, decided to take drug $^{c}$ & 0 & 0 & 0 & \\
\hline Total follow-up informed decisions & $65(16.9 \%)$ & $12(11.8 \%)$ & $8(8.0 \%)$ & $X^{2}(2)=5.40, P=0.067$ \\
\hline \multicolumn{5}{|l|}{ Latent knowledge informed decisions ${ }^{\mathrm{b} d}$} \\
\hline Negative attitudes, decided against drug & $131(34.2 \%)$ & $3(2.9 \%)$ & - & \\
\hline Neutral attitudes, no decision made & $36(9.4 \%)$ & 0 & - & \\
\hline Positive attitudes, decided to take drug $^{c}$ & 0 & 0 & - & \\
\hline Total latent informed decisions & $167(43.6 \%)$ & $3(2.9 \%)$ & & $X^{2}(1)=58.54, P<0.001$ \\
\hline
\end{tabular}

${ }^{a}$ Three-month control group did not complete measures at post-test; In all cases of informed decision making level of knowledge needs to be sufficient. Attitudes should align with likelihood of taking the drug. Participants in the three-month control group did not answer knowledge questions at post-test; ${ }^{\mathrm{C}}$ At three 3 month follow-up, of the two participants who decided to take raloxifene, one had sufficient knowledge but neutral attitudes and one had insufficient knowledge and positive attitudes. ${ }^{\mathrm{d}}$ Latent informed decisions consisted of sufficient post-test knowledge, and aligned attitudes and decisions at follow-up.

\section{Follow-up knowledge, attitudes and behavior}

In the follow-up survey, we assessed knowledge, attitudes and uptake of tamoxifen and raloxifene over the previous three months. While $62 \%$ of the intervention group met criteria for sufficient knowledge at post-test, only 25\% met these criteria at follow-up, showing a steep decline in retention of information (Table 2). Sufficient knowledge was demonstrated by $15 \%$ of standard control participants and $12 \%$ of three-month control participants. Differences between the intervention and control groups were statistically significant, $\left(\mathrm{X}^{2}(2)=10.71, P=.005\right)$.

Attitudes toward uptake of chemoprevention were generally negative in all groups (75\% intervention, 70\% standard control, 63\% three-month control (see Table 2) and did not differ across groups, $\mathrm{X}^{2}(4)=7.84, P=.098$.

Intervention participants were more likely to report having made a decision (versus being undecided) about starting chemoprevention, $\mathrm{X}^{2}(4)=29.06, P<.001$. Among intervention participants, two women (1\%) decided to take raloxifene, $45 \%$ were undecided, and 55\% decided against chemoprevention drugs. No standard control participants decided to take a drug (0\%), 66\% were undecided and 34\% decided against chemoprevention drugs. No three-month control group participants decided to take a drug (0\%), $70 \%$ were undecided and $30 \%$ decided against chemoprevention drugs (Table 2).

Participants in the intervention group most often showed alignment between attitudes and decisions $(68 \%$ intervention, 55\% standard control, 54\% three-month control), $X^{2}(2)=9.85, P=0.007$ (data not shown).

\section{Follow-up informed choice}

At three months, $17 \%$ of the intervention group's choices about uptake of chemoprevention could be considered 'informed' according to our definition (Table 3). These were all decisions to not take tamoxifen or raloxifene. Two women decided to use raloxifene, but these choices were uninformed because they either had insufficient knowledge $(n=1)$ or a neutral attitude $(n=1)$. In the control groups, $12 \%$ (standard control) and $8 \%$ (three-month control) of choices were informed (Table 3). Differences in rates of informed choices between groups were statistically insignificant, $\mathrm{X}^{2}(2)=5.40, P=0.067$.

\section{Latent informed choices}

Because knowledge was so low at follow-up and because it is likely that people made decisions based on post-test (latent) knowledge [23] we also examined informed decision making at three months using the post-test levels of sufficient knowledge. This way, $44 \%$ of the intervention group's choices about uptake of chemoprevention at three months could be considered 'informed', whereas only $3 \%$ of the standard control groups' choices were informed, $\mathrm{X}^{2}(1)=58.54, P<0.001$ (Table 3 ).

\section{Discussion}

In this study, Marteau's model [17] was used to determine whether the DA increased the number of informed choices about uptake of tamoxifene and raloxifene. In fact, our data revealed that women given a DA were more likely to have made an informed choice about uptake of 
tamoxifen and raloxifene than women who did not view the DA. Also, fewer women in the intervention group remained undecided about uptake of the drugs. As expected, three months after baseline the rate of informed decision making about actual uptake was still marginally higher in women who had received the DA, particularly because of declining knowledge levels. However, overall, levels of informed decision making are strikingly low.

Since most respondents had negative attitudes toward uptake of tamoxifen and raloxifene and most decided not to take chemoprevention drugs, uninformed choices were mainly related to insufficient knowledge. One potential reason for relatively low rates of knowledge in the group receiving the DA is that each drug had five risks and two benefits presented. The amount of information conveyed may have been overwhelming and reduced people's recall, even though we asked about gist-level information [23].

The rate of informed choices in the intervention group decreased from 54\% (post-test) to 18\% (threemonth follow-up), but attitudes did not change from post-test to follow-up. The observed decline in informed choices is mainly due to decreased knowledge scores over time and measuring latent decision-making appears to be useful. This raises an interesting question - how long are decision-makers supposed to remember gist-level information once they have come to a decision?

Another issue is the important influence of the definition of what exactly constitutes 'sufficient decisionrelevant knowledge' on the resulting proportion of informed choice. Consensus is needed on the levels of knowledge and specific content necessary to make informed decisions. A drawback of the complicated nature of the information being provided, and thus a limitation of this study, is that there were not enough participants with more than 50\% knowledge retention to examine differences between groups.

One might expect that women who consider taking chemoprevention drugs are more likely to remember information because it is relevant to their decision, whereas women who have already decided not to take the drugs may be less motivated to remember the information. However, we did not find this effect.

Traditionally two kinds of informed choices are distinguished: sufficient decision-relevant knowledge combined with either positive attitudes and acceptance of the preventive measure or negative attitudes and a decline of the preventive measure [17]. We identified a third type of informed choice, which is the combination of sufficient knowledge, neutral attitudes and being undecided about uptake of the preventive measure. The question is whether this third combination indeed reflects an informed choice rather than ambivalent attitudes, since - as shown by earlier research - ambivalence may lead to postponing decision making [26]. We recommend further study into this topic.

It has often been shown that DAs lead to increased levels of knowledge in those who have used them [27]. While many studies of DAs examine changes in knowledge, attitudes, intentions and behavior, few examine the relationship between knowledge and the concordance between attitudes, intentions, and behavior. Even for wellknown population-based screening programs, such as breast or cervical cancer screening, interventions specifically aimed at improving informed decision-making are limited $[28,29]$. This study, therefore, represents a valuable contribution to the literature. Our study has several limitations related to generalizability of the findings. First, despite oversampling eligible African American women, participants were mostly White. Other chemoprevention studies have also encountered this problem $[1,5,6,10,21]$. Second, we used an online DA, which can ultimately increase intervention reach, but lack of Internet access or discomfort with using the Internet likely narrowed the pool of potential participants and possibly directed access to a more educated sample. However, findings of previous research comparing Internet samples to other samples are inconsistent in this regard [30,31]. Third, we assessed attitudes with one item. Although this single item enabled the registration of negative attitudes considering own participation in the intervention - which is often not the case when attitudes are being assessed we acknowledge that using one item is a bit limited.

While the above limitations decrease external validity of our study, including two control groups significantly strengthens internal validity. The standard control group allows us to test the effects of the DA compared to not receiving any information about tamoxifen and raloxifene, while the three-month control group allows us a clean control group to evaluate the impact of the DA over time. Our results may generalize to other insured patients, as we recruited participants from two geographically diverse health plan populations.

\section{Practice implications}

Women given a DA describing risks and benefits of tamoxifen and raloxifene were significantly more likely to make informed decisions about undergoing chemoprevention for breast cancer. The intervention materials impacted not only knowledge but also alignment of attitudes with decisions. The online DA format makes this a potentially valuable adjunct in clinical practice, since women could utilize it prior to clinic visits. Finally, this study suggests a valuable way to evaluate the effectiveness of DAs.

\section{Conclusions}

While informed decisions cannot, by definition, be made without sufficient relevant knowledge [17], it is also 
important that attitudes align with intentions and actual behavior. In this study, women in the intervention group more often had made decisions about uptake of tamoxifen and raloxifene that aligned with their attitudes.

\section{Abbreviations}

BCRAT: Breast Cancer Risk Assessment Tool; DA: decision aid; MMIC Multidimensional Measure oflnformed Choice; STAR: Study of Tamoxifen and Raloxifene.

\section{Competing interests}

The authors declare that they have no competing interests.

\section{Authors' contributions}

IJK and AFF performed the statistical analysis and drafted the manuscript. PU, BZF and DS conceived of the study and participated in its design and coordination. SMG, JBM and SHA participated in the design and coordination of the study and contributed to the data-collection. AF conceived of the study, participated in its design and coordination and participated in drafting the manuscript. All authors have been involved in revising the manuscript. All authors have read and approved the final manuscript.

\section{Acknowledgements}

We would like to thank the Center for Heath Communication Research (especially Michael Nowak) who did an excellent job turning our DA into a well designed and easily navigated web site. We would also like to thank Roy Pardee and Rick Krajenta for their assistance with compiling the databases of eligible participants. Finally, we are very grateful to all the women who participated in this study.

Financial support

Financial support for this study was provided by a grant from the National Institutes of Health (P50 CA101451). At the time of study design and implementation, Drs. Fagerlin and Smith were supported by MREP early career awards from the U.S. Department of Veterans Affairs. Dr. ZikmundFisher is supported by a career development award from the American Cancer Society (MRSG-06-130-01-CPPB). Dr. Hayes received support from Fashion Footwear Charitable Foundation of New York/QVC Presents Shoes on Sale. Dr. Korfage was funded through a fellowship of the Dutch Cancer Society (reference EMCR 2008-4339). The funding agreements ensured the authors' independence in designing the study, interpreting the data, and publishing the report.

\section{Authors' details}

${ }^{1}$ Erasmus Medical Center, Department of Public Health, Dr. Molewaterplein 5, 3015 GE Rotterdam, the Netherlands. ${ }^{2}$ Center for Bioethics and Social Sciences in Medicine, University of Michigan, 300 North Ingalls, Ann Arbor, Ml 48106-1248, USA. ${ }^{3}$ Division of General Internal Medicine, University of Michigan, 2800 Plymouth Road, Ann Arbor, MI 48109-2800, USA. ${ }^{4}$ Research Center for Group Dynamics, Institute for Social Research, 426 Thompson Streeet, Ann Arbor, Ml 48106-1248, USA. ${ }^{5}$ Fuqua School of Business, Duke University, 100 Fuqua Drive, Durham, NC 27708-0120, USA. ${ }^{6}$ Sanford School of Public Policy, Duke University, 201 Science Drive, Durham, NC 27708, USA ${ }^{7}$ Department of Health Behavior and Health Education, University of Michigan, 1415 Washington Hts, Ann Arbor, Ml 48109-2029, USA. ${ }^{8}$ Risk Science Center, University of Michigan, 1415 Washington Hts, Ann Arbor, MI 48109-2029, USA. ${ }^{9}$ Group Health Research Institute, 1730 Minor Avenue, Seattle, WA 98101, USA. ${ }^{10}$ Department of Preventive Medicine, Stony Brook University, 101 Nicolls Road, Stony Brook, NY 11794, USA. ${ }^{11}$ Departments of Public Health Sciences \& Women's Health, Henry Ford Hospital, 2799 W Grand Blvd, Detroit, Ml 48202, USA. ${ }^{12}$ VA Ann Arbor Center for Clinical Management Research, 2215 Fuller Road, Ann Arbor, MI 48105, USA.

${ }^{13}$ Department of Psychology, University of Michigan, 530 Church Street, Ann Arbor, Ml 48109-1043, USA.

Received: 19 April 2013 Revised: 8 May 2013

Accepted: 3 September 2013 Published: 3 September 2013
References

1. Fisher B, Costantino JP, Wickerham DL, Redmond CK, Kavanah M, Cronin WM, Vogel V, Robidoux A, Dimitrov N, Atkins J, Daly M, Wieand S, Tan-Chiu E, Ford L, Wolmark N: Tamoxifen for prevention of breast cancer: report of the National Surgical Adjuvant Breast and Bowel Project P-1 Study. J Natl Cancer Inst 1998, 90:1371-1388.

2. Fisher B, Costantino JP, Wickerham DL, Cecchini RS, Cronin WM Robidoux A, Bevers TB, Kavanah MT, Atkins JN, Margolese RG, Runowicz CD, James JM, Ford LG, Wolmark N: Tamoxifen for the prevention of breast cancer: current status of the National Surgical Adjuvant Breast and Bowel Project P-1 Study. J Natl Cancer Inst 2005, 97:1652-1662.

3. Jordan VC: Tamoxifen: the herald of a new era of preventive therapeutics. J Natl Cancer Inst 1997, 89:747-749.

4. Bober SL, Hoke LA, Duda RB, Regan MM, Tung NM: Decision-making about tamoxifen in women at high risk for breast cancer: clinical and psychological factors. J Clin Oncol 2004, 22:4951-4957.

5. Port E, Montgomery L, Heerdt A, Borgen P: Patient reluctance toward tamoxifen use for breast cancer primary prevention. Ann Surg Oncol 2001, 8:580-585

6. Stacey D, O'Connor AM, DeGrasse C, Verma S: Development and evaluation of a breast cancer prevention decision aid for higher-risk women. Health Expect 2003, 6:3-18.

7. Fagerlin A, Zikmund-Fisher BJ, Smith DM, Nair V, Derry HA, McClure JB, Greene S, Stark A, Hensley Alford S, Lantz P, Hayes DF, Wiese C, Claud Zweig S, Pitsch R, Jankovic A, Ubel PA: Women's decisions regarding tamoxifen for breast cancer prevention: responses to a tailored decision aid. Breast Cancer Res Treat 2010, 119:613-620.

8. Fagerlin A, Dillard AJ, Smith DM, Zikmund-Fisher BJ, Pitsch R, McClure JB, Greene S, Hensley Alford S, Nair V, Hayes DF, Wiese C, Ubel PA: Women's interest in taking tamoxifen and raloxifene for breast cancer prevention: response to a tailored decision aid. Breast Cancer Res Treat 2011, 127:681-688.

9. Kaplan CP, Haas JS, Pérez-Stable EJ, Gregorich SE, Somkin C, Des Jarlais G, Kerlikowske K: Breast cancer risk reduction options: awareness, discussion, and use among women from rour ethnic groups. Cancer Epidemiol Biomarkers Prev 2006, 15:162-166.

10. Melnikow J, Paterniti D, Azari R, Kuenneth C, Birch S, Kuppermann M, Nuovo J, Keyzer J, Henderson S: Preferences of women evaluating risks of tamoxifen (POWER) study of preferences for tamoxifen for breast cancer risk reduction. Cancer 2005, 103:1996-2005.

11. Metcalfe KA, Snyder C, Seidel J, Hanna D, Lynch HT, Narod S: The use of preventative measures among healthy women who carry BRCA1 or BRCA2 mutation. Fam Cancer 2005, 4:97-103.

12. Salant T, Ganschow PS, Olopade OI, Lauderdale DS: Why take it if you don't have anything? Breast cancer risk perceptions and prevention choices at a public hospital. J Gen Intern Med 2006, 21:779-785.

13. Donovan $\mathrm{R}$, Jalleh $\mathrm{G}$, Jones $\mathrm{S}$ : The word 'cancer': reframing the context to reduce anxiety arousal. Aust N Z J Public Health 2003, 7:291-293.

14. Paterniti DA, Melnikow J, Nuovo J, Henderson S, DeGregorio M, Kuppermann M, Nease R: "I'm going to die of something anyway": Women's perceptions of tamoxifen for breast cancer risk reduction. Ethnic Dis 2005, 15:365-372.

15. Promoting Disease Management in Medicare: Hearings before the Subcommittee on Health of the House Committee on Ways and Means, 107th Cong, 2nd Sess. 2002, (Testimony of J. E. Wennberg).

16. Osterlie W, Solbjor M, Skolbekken JA, Hofvind S, Saetnan AR, Forsmo S: Challenges of informed choice in organised screening. J Med Ethics 2008, 34:e5.

17. Marteau TM, Dormandy E, Michie S: A measure of informed choice. Health Expect 2001, 4:99-108.

18. Michie S, Dormandy E, Marteau TM: The multi-dimensional measure of informed choice: a validation study. Patient Educ Couns 2002, 48:87-91.

19. O'Connor A, O'Brien-Pallas LL: Decisional conflict. In Nursing Diagnosis and Intervention. Edited by: McFarland GK, McFarlane EA. Toronto: C.V. Mosby Company; 1989:573-588.

20. Gail MH, Brinton LA, Byar DP, Donald K, Green SB, Schairer C, Mulvihill JJ: Projecting individualized probabilities of developing breast cancer for white females who are being examined annually. J Natl Cancer Inst 1989, 81:1879-1886.

21. Vogel VG, Costantino JP, Wickerham DL, Cronin WM, Cecchini RS, Atkins JN, Bevers TB, Fehrenbacher L, Pajon ER, Wade $J$, Robidoux A, Margolese RG, 
James J, Lippman SM, Runowicz CD, Ganz PA, Reis SE, McCaskill-Stevens W, Ford LG, Jordan VC, Wolmark N, National Surgical Adjuvant, Breast Bowel Project: Effects of tamoxifen vs raloxifene on the risk of developing invasive breast cancer and other disease outcomes. JAMA 2006, 295:2727-2741

22. van den Bergh KAM, Essink-Bot M-L, van Klaveren RJ, de Koning HJ: Informed decision making does not affect health-related quality of life in lung cancer screening (NELSON trial). Eur J Cancer 2010, 46:3300-3306.

23. Reyna VF: A theory of medical decision making and health: fuzzy trace theory. Med Decis Making 2008, 28:850-865.

24. Fagerlin A, Zikmund-Fisher BJ, Ubel PA, Jankovic A, Derry HA, Smith DM: Measuring numeracy without a math test: development of the subjective numeracy scale. Med Decis Making 2007, 27:672-680.

25. Zikmund-Fisher BJ, Smith DM, Ubel PA, Fagerlin A: Validation of the subjective numeracy scale (SNS): effects of low numeracy on comprehension of risk communications and utility elicitations. Med Decis Making 2007, 27:663-671.

26. Conner M, Sparks P: Ambivalence and attitudes. Eur Rev Soc Psychol 2002, 12:37-70.

27. Stacey $\mathrm{D}$, Bennett $\mathrm{CL}$, Barry MJ, Col NF, Eden KB, Holmes-Rovner M, Llewellyn-Thomas H, Lyddiatt A, Legare F, Thomson R: Decision aids for people facing health treatment or screening decisions. Cochrane Database Syst Rev 2011, , 10: CD001431.

28. Mathieu E, Barratt A, Davey HM, McGeechan K, Howard K, Houssami N: Informed choice in mammography screening: a randomized trial of a decision aid for 70-year-old women. Arch Intern Med 2007, 167:2039-2046.

29. Smith SK, Trevena L, Simpson JM, Barratt A, Nutbeam D, McCaffery KJ: A decision aid to support informed choices about bowel cancer screening among adults with low education: randomised controlled trial. BMJ 2010, 341:C5370

30. Bandilla W, Bosnjak M, Altdorfer P: Survey administration effects? Soc Sci Computer Rev 2003, 21:235-243.

31. Etter JF, Perneger TV: A comparison of cigarette smokers recruited through the Internet or by mail. Int I Epidemiol 2001, 30:521-5.

doi:10.1186/bcr3468

Cite this article as: Korfage et al:: Informed choice about breast cancer prevention: randomized controlled trial of an online decision aid intervention. Breast Cancer Research 2013 15:R74.

\section{Submit your next manuscript to BioMed Central and take full advantage of:}

- Convenient online submission

- Thorough peer review

- No space constraints or color figure charges

- Immediate publication on acceptance

- Inclusion in PubMed, CAS, Scopus and Google Scholar

- Research which is freely available for redistribution

Submit your manuscript at www.biomedcentral.com/submit 